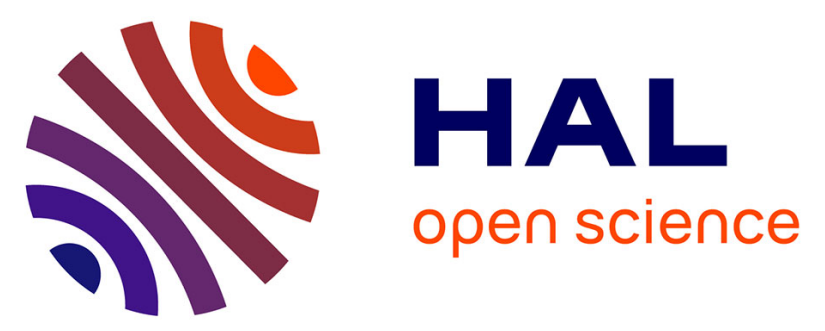

\title{
Modeling the temporal variability of zinc concentrations in zinc roof runoff-experimental study and uncertainty analysis
}

\author{
Jérémie Sage, E. El Oreibi, M. Saad, Marie-Christine Gromaire
}

\section{To cite this version:}

Jérémie Sage, E. El Oreibi, M. Saad, Marie-Christine Gromaire. Modeling the temporal variability of zinc concentrations in zinc roof runoff-experimental study and uncertainty analysis. Environmental Science and Pollution Research, 2016, 23 (16), pp.16552-16566. 10.1007/s11356-016-6827-6 . hal01685970

HAL Id: hal-01685970

https://hal-enpc.archives-ouvertes.fr/hal-01685970

Submitted on 17 Jul 2018

HAL is a multi-disciplinary open access archive for the deposit and dissemination of scientific research documents, whether they are published or not. The documents may come from teaching and research institutions in France or abroad, or from public or private research centers.
L'archive ouverte pluridisciplinaire HAL, est destinée au dépôt et à la diffusion de documents scientifiques de niveau recherche, publiés ou non, émanant des établissements d'enseignement et de recherche français ou étrangers, des laboratoires publics ou privés. 
Jérémie Sage, Elissar El Oreibi, Mohamed Saad, Marie-Christine Gromaire (2016). Modelling the temporal variability of zinc concentrations in zinc roof runoff - Experimental study and uncertainty analysis, Environmental Science and Pollution Research, pp. 1-15.

The final publication is available at Springer via http://dx.doi.org/10.1007/s11356-016-6827-6 


\title{
MODELLING THE TEMPORAL VARIABILITY OF ZINC CONCENTRATIONS IN ZINC ROOF RUNOFF - EXPERIMENTAL STUDY AND UNCERTAINTY ANALYSIS
}

\author{
SAGE Jérémie ${ }^{1,2^{*},}$ EL OREIBI Elissar ${ }^{1}$, SAAD $_{\text {Mohamed }}{ }^{1}$, GROMAIRE Marie-Christine $^{1}$ \\ ${ }^{1}$ Université Paris Est, LEESU, UMR MA 102 - Agro ParisTech, Ecole des Ponts ParisTech, Cité Descartes - 6-8 \\ av. Blaise Pascal, 77455, Champs-sur-Marne, France \\ ${ }^{2}$ CEREMA (National center for studies and expertise on risks, environment, mobility, and urban and country \\ planning) - DT Ile-de-France, 12 rue Teisserenc de Bort, 78180, Trappes, France \\ *Corresponding author: jeremie.sage[at]cerema.fr
}

\begin{abstract}
This study investigates the temporal variability of zinc concentrations from zinc roof runoff. The influence of rainfall characteristics and dry period duration is evaluated by combining laboratory experiment on small zinc sheets and in-situ measurements under real weather conditions from a $1.6 \mathrm{~m}^{2}$ zinc panel. A reformulation of a commonly used conceptual runoff quality model is introduced and its ability to simulate the evolution of zinc concentrations is evaluated. A systematic and sharp decrease from initially high to relatively low and stable zinc concentrations after 0.5 to 2 millimetres of rainfall is observed for both experiments, suggesting that highly soluble corrosion products are removed at early stages of runoff. A moderate dependence between antecedent dry period duration and the magnitude of zinc concentrations at the beginning of a rain event is evidenced. Contrariwise, results indicate that concentrations are not significantly influenced by rainfall intensities. Simulated rainfall experiment nonetheless suggests that a slight effect of rainfall intensities may be expected after the initial decrease of concentrations. Finally, this study shows that relatively simple conceptual runoff quality models may be adopted to simulate the variability of zinc concentrations during a rain event and from a rain event to another.
\end{abstract}

KEYWORDS: Accumulation; Corrosion; Dissolution; Dry period; Model; Rainfall intensity; Wash-off, ZincRoof

\section{INTRODUCTION}

Contaminants associated with stormwater runoff have been identified as a major source of diffuse pollution. Over the last decades, several studies have investigated the sources of contaminants in urban areas and high trace metal concentrations were generally reported in roof runoff, due to the corrosion of metal gutter or roofing materials (Gnecco et al., 2005; Gromaire et al., 2001; Zobrist et al., 2000). Among these materials, zinc sheets or zinc coated steel have been widely used for building applications and remain a convenient, affordable and aesthetic solution for large roofing areas. Zinc concentrations in the runoff originating from such surfaces have been extensively studied and were often shown to exceed by several orders of magnitude environmental quality 
standards (EQS) set by the European Water Framework Directive or to adversely affect the health of sensitive freshwater species (Bertling et al., 2006; Förster, 1996; Karlén et al., 2001; Persson and Kucera, 2001). In the urban environment, the contribution of zinc or zinc coated structures to total metal emissions was often found to be significant (Gromaire et al., 2011; Reiss et al., 2004) and the need to manage runoff originating from these materials is today well accepted.

The implementation of stormwater source-control systems (such as biofiltration or other treatment devices) promoting adsorption on artificial or natural substrates is believably a relevant option to limit the discharge of zinc to surface waters (as for small catchments zinc is predominantly dissolved) (Bressy et al., 2012). Metal concentrations, however, usually exhibit large fluctuations during a rain event (Schriewer et al., 2008) or from an event to another (Gromaire et al., 2011; He, 2002) and the understanding of this temporal variability is essential for the development of suitable management practices.

Laboratory experiments on copper and zinc panels revealed that availability and solubility of corrosion products probably governs the variability of metal concentrations in runoff (He et al., 2001). It has hence been suggested that antecedent dry period between rain events could partly explain the differences in metal concentrations from an event to another (Gromaire et al., 2011; He et al., 2001) although the influence of this parameter has not systematically been verified in field experiments (Athanasiadis et al., 2010; Schriewer et al., 2008). Literature results also indicated that the dissolution of these corrosion products strongly depends on rain event characteristics and that metal loads are largely controlled by runoff volumes (Gromaire et al., 2011; He et al., 2001). Event-mean-concentrations have generally been reported to decrease with increasing runoff volumes or rainfall duration (Gromaire et al., 2011; He et al., 2001; Robert-Sainte, 2009; Schriewer et al., 2008). Few studies have however investigated the effect of rainfall on the variations in metal concentrations during a rain event. A strong decrease of metal (zinc or copper) concentrations is usually observed with the first millimetres of runoff (He et al., 2001; Schriewer et al., 2008; Zobrist et al., 2000), which partly explains the relation between event duration or volumes and event-mean-concentrations. Nonetheless, previous studies revealed that rainfall intensities could as well influence the magnitude of concentrations (especially at early stages of runoff) as a result of (1) variations in the time of contact between rainwater and metal surfaces or (2) changes in the ratio between runoff volume and contact area (He et al., 2001; Schriewer et al., 2008; Wicke, 2014). As a matter of fact, experiments on the impacts of roof length and inclination rather suggest that time of contact has only a limited influence on metal concentrations as compared to the runoff volume to contact area ratio (Bielmyer et al., 2012; Robert-Sainte, 2009).

Although rainfall intensity and antecedent dry period duration have been reported as key parameters, their effect is hence not completely understood. Furthermore, while equations have been introduced to describe the wash-off dynamic of sediments or particulate bound pollutants from urban surfaces (Alley and Smith, 1981; Tsihrintzis and Hamid, 2001; Vezzaro and Mikkelsen, 2012) and successfully applied for the comparison of different runoff management scenarios (Lee et al., 2012; Vezzaro et al., 2015), no models have yet been proposed to simulate the variability of concentrations in zinc roof runoff during rain events. The purpose of this study is therefore (1) to improve the understanding of zinc emission dynamics during rainfall events and, more specifically, (2) to investigate the effect of rainfall characteristics and antecedent dry period duration on the variability of zinc 
concentrations so as (3) to come up with a model to replicate these concentrations, which would be of great interest for the development of efficient stormwater management practices or to assess the effect of stormwater discharge on receiving waters.

The influence of rainfall characteristics and dry period duration is evaluated by combining laboratory experiment on small zinc sheets (to simulate specific intensities and dry period durations) and in-situ measurements under real weather conditions from a $1.6 \mathrm{~m}^{2}$ zinc panel. A reformulation of a commonly used "accumulation and washoff" runoff quality model is introduced to simulate general trends in zinc runoff dynamics over long rainfall periods and its ability to replicate zinc concentrations for both the simulated rainfall and the in-situ experiment is investigated. Possible applications of this model include accounting for the variability of zinc concentrations in runoff for an accurate design of stormwater source-control systems or assessing the impact of zinc roof runoff discharge on receiving waters. Rather than providing precise concentration predictions for a specific rainfall event, the purpose of this model, deliberately kept relatively simple, is therefore to simulate realistic inter and intra-event variations of zinc concentrations from easily available data (eg. rainfall measurement). Because large uncertainties are usually associated with stormwater quality modelling, it has been recently suggested that model evaluation from direct calibration method is generally inappropriate (Dotto et al., 2011; Freni et al., 2009; Kanso et al., 2006). A Monte Carlo Markov Chain (MCMC) sampling method, with rigorous bias description, is thus implemented to evaluate the uncertainties associated with calibration and to discuss the reliability of the model.

\section{EXPERIMENTAL SETUP}

\subsection{SiMULATED RAINFALL EXPERIMENT}

The laboratory experiment was conducted so as to evaluate separately the effect of rainfall intensity and dry period duration between rain events. Small panels $(20 \times 50 \mathrm{~cm})$ were cut off from a $1 \mathrm{~m}^{2}$ zinc sheet, previously cleaned with acetone and exposed to atmospheric conditions for a 2.5 month period (09/03/2014 to 21/05/2014) at a peri-urban site located in Champs-sur-Marne (nearby Paris, France). During this period, average atmospheric $\mathrm{NO}_{2}$ and $\mathrm{O}_{3}$ concentrations (recorded $3.5 \mathrm{~km}$ from the site) were $32 \mu \mathrm{g} / \mathrm{m}^{3}$ and $56 \mu \mathrm{g} / \mathrm{m}^{3}$ and the total rainfall depth was $58 \mathrm{~mm}$. This pre-exposure period was stopped after a large rain event (16.8 $\mathrm{mm}$ over 12h), which presumably washed-off easily soluble corrosion products from the surface of the panel. After 21/05/2014, zinc panels were stored outside but protected from rainfall so as to replicate dry weather conditions.

Three rainfall intensities $(5,9$ and $17 \mathrm{~mm} / \mathrm{h})$ and three antecedent dry period durations $(2,5$ and 21 days) were tested for the experiment. A statistical analysis of a 15-year meteorological record from Paris region indicates that approximately $50 \%, 80 \%$ and $90 \%$ of the rainfall volumes are produced for intensities smaller than 5,9 and $17 \mathrm{~mm} / \mathrm{h}$ and that the frequency of periods of 2,5 and 21 days without precipitation is 44,13 and 0.2 occurrences per year. Selected rainfall intensities and antecedent dry period duration therefore encompass usual to less frequent exposure conditions in Paris region. Rainfall was simulated with a SPRAI-SAS spinning disk spraying system, raindrop size and rainfall intensities being controlled by water feed rate and nozzle rotation speed. The device was calibrated for the selected rainfall intensities and verified to ensure homogeneous spraying of the zinc panels. The artificial rainwater used in this experiment consists of a 1:21 mixture of mineral 
and deionized water. Its ionic composition is presented in table 1, and approximately matches the concentrations reported in Paris conurbation (Van de Voorde, 2012). The corresponding pH value (6.8) is representative of the average conditions in Paris region for total atmospheric fallout, where event mean values ranging from 5.7 to 8.1 have been reported, with site mean values between 6.4 and 7.1 (Bressy, 2010; Gromaire et al., 2015).

\begin{tabular}{ccccccc}
\hline $\begin{array}{c}\mathrm{Ca}^{2+} \\
(\mathrm{mg} / \mathrm{l})\end{array}$ & $\begin{array}{c}\mathrm{Na}^{+} \\
(\mathrm{mg} / \mathrm{l})\end{array}$ & $\begin{array}{c}\mathrm{K}^{+} \\
(\mathrm{mg} / \mathrm{l})\end{array}$ & $\begin{array}{c}\mathrm{SO}_{4}{ }^{2-} \\
(\mathrm{mg} / \mathrm{l})\end{array}$ & $\begin{array}{c}\mathrm{HCO}_{3}^{-} \\
(\mathrm{mg} / \mathrm{l})\end{array}$ & $\begin{array}{c}\mathrm{Cl}^{-} \\
(\mathrm{mg} / \mathrm{l})\end{array}$ & $\mathrm{pH}$ \\
0.55 & 0.55 & 0.29 & 0.38 & 3.4 & 0.64 & 6.8 \\
\hline
\end{tabular}

Table 1 Major ion concentrations and $\mathrm{pH}$ of the artificial rainwater used for the simulated rainfall experiment

The effect of the three different rainfall intensity classes (i) was tested for the three antecedent dry period durations $\left(\mathrm{T}_{\mathrm{DRY}}\right)$. For each combination of $\mathrm{i}$ and $\mathrm{T}_{\mathrm{DRY}}$, zinc concentrations were monitored for two panels installed under the rainfall simulator with a $5^{\circ}$ inclination. $8 \times 30 \mathrm{ml}$ runoff samples were collected on each panel at different times during each experiment, targeting different fractions of the cumulative rainfall volume (corresponding runoff fraction are presented in table 2). Effective rainfall intensities were verified during each experiment evidencing slight deviations from targeted rainfall intensities (e.g. 3.9 to 5.8, 7.1 to 10.5 and 16.3 to $17.2 \mathrm{~mm} / \mathrm{h}$ for the $4.5,9$ and $17 \mathrm{~mm} / \mathrm{h}$ intensity classes), resulting in small differences in the actual cumulative runoff volume associated with each sample for a given targeted intensity.

\begin{tabular}{|c|c|c|}
\hline \multirow[t]{2}{*}{ Sample $N^{\circ}$} & \multicolumn{2}{|c|}{ Fraction of runoff associated with each sample ${ }^{1}$} \\
\hline & Rainfall intensity $=4.5 \mathrm{~mm} / \mathrm{h}$ & Rainfall intensity $=9$ or $17 \mathrm{~mm} / \mathrm{h}$ \\
\hline 1 & $0.4-0.8 \mathrm{~mm}$ & $0.3-0.5 \mathrm{~mm}$ \\
\hline 2 & $0.8-1.2 \mathrm{~mm}$ & $0.5-0.8 \mathrm{~mm}$ \\
\hline 3 & $1.2-1.6 \mathrm{~mm}$ & $0.8-1.1 \mathrm{~mm}$ \\
\hline 4 & $2.0-2.4 \mathrm{~mm}$ & $1.4-1.7 \mathrm{~mm}$ \\
\hline 5 & $3.2-3.6 \mathrm{~mm}$ & $2.3-2.6 \mathrm{~mm}$ \\
\hline 6 & $5.8-6.2 \mathrm{~mm}$ & $4.1-4.4 \mathrm{~mm}$ \\
\hline 7 & $8.3-8.6 \mathrm{~mm}$ & $5.9-6.2 \mathrm{~mm}$ \\
\hline 8 & $15.8-16.2 \mathrm{~mm}$ & $11.3-11.6 \mathrm{~mm}$ \\
\hline
\end{tabular}

Table 2 Runoff fractions selected for the simulated rainfall experiment (because of deviations in the artificial rainfall intensity, different fractions were sampled for the $4.5 \mathrm{~mm} / \mathrm{h}$ intensity)

\subsection{IN-SITU EXPERIMENT}

The release of zinc from a $1.6 \mathrm{~m}^{2}$ (= projected area, flow length $\left.\approx 4 \mathrm{~m}\right) 8$ years old zinc panel was investigated during a 5 month period (from May 2014 to September 2014) under real rainfall conditions. Like for the previous experiment, studied site is located in Champs-sur-Marne. The panel was installed on the top of a building with a $5^{\circ}$ angle from the horizontal and rainfall measurements were performed from a rain gauge $(0.2 \mathrm{~mm}$ precision) located few meters from the panel.

The system adopted here for runoff sampling is similar to the one of Yaziz et al. (1989), and is designed to collect different fractions of the runoff volume (cf. Figure 1): 


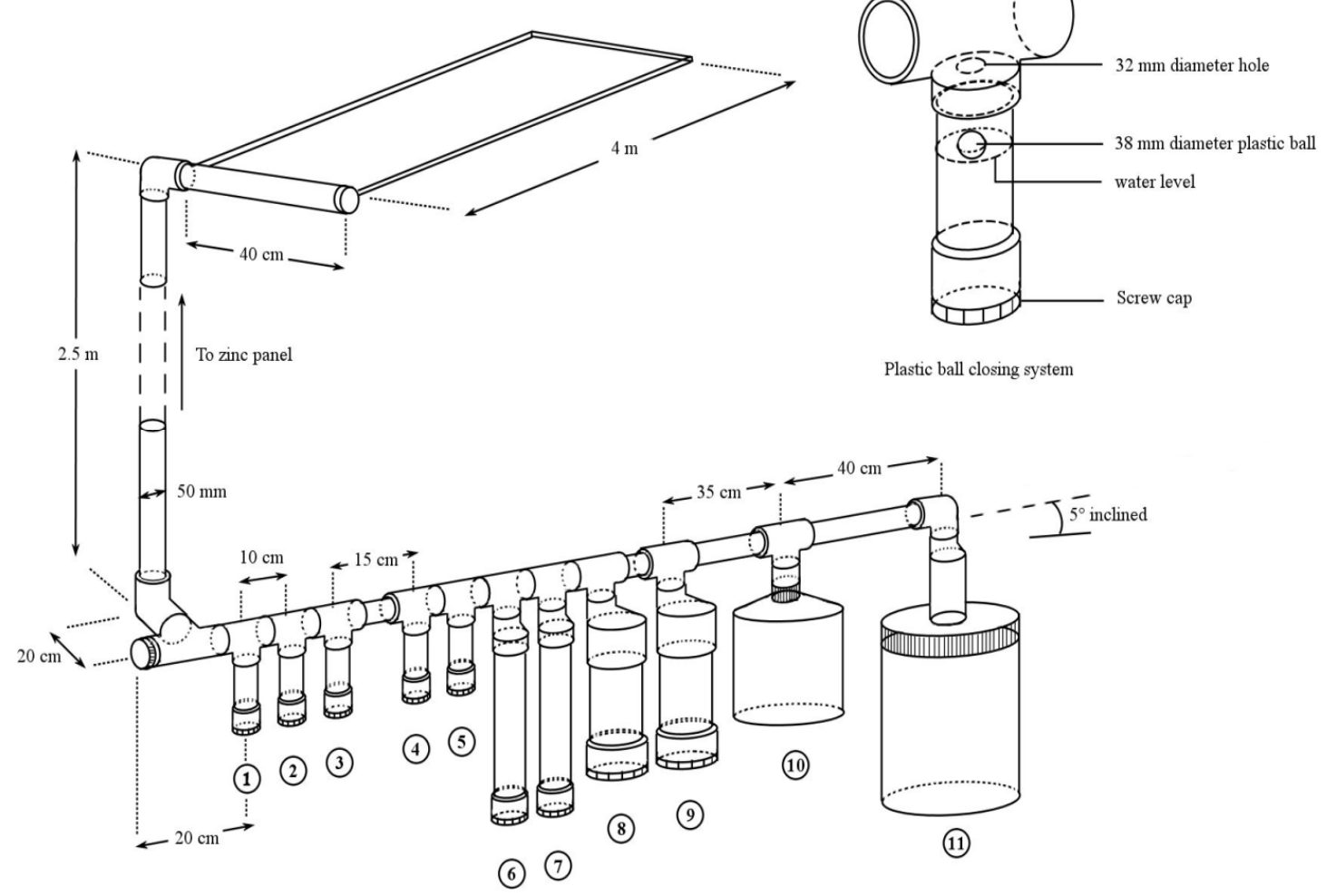

Fig1 Sampling system for the in-situ experiment

Runoff originating from the zinc panel was collected through a PVC gutter and directed to a sampling device (3m below) which consisted of 11 PVC containers (with different capacities) connected with an inclined PVC pipe $\left(+5^{\circ}\right.$ from the horizontal). Water collected through the gutter progressively moved in the PVC pipe (the water is assumed to move as a piston) and successively filled the PVC containers, in which a floating plastic ball was used as a blocking system (cf. Figure 1). Because zinc concentrations were previously shown to vary very quickly in the first millimetres of runoff (He, 2002; Schriewer et al., 2008), the volume of each container progressively became larger as the cumulative runoff volume in the sampling system increased. Complete information about collected volumes for each fraction of runoff can be found in table 3 .

\begin{tabular}{cccc}
\hline Sample $\mathrm{N}^{\circ}$ & $\begin{array}{c}\text { Collected volume } \\
(\mathrm{mm})\end{array}$ & $\begin{array}{c}\text { Cumulative runoff volume } \\
\text { (mm) }\end{array}$ & $\begin{array}{c}\text { Additional volume }^{2} \\
\text { (mm) }\end{array}$ \\
\cline { 2 - 4 } 1 & 0 to 0.21 & 0.21 & 0.09 \\
2 & 0.21 to 0.43 & 0.43 & 0.19 \\
3 & 0.43 to 0.64 & 0.64 & 0.33 \\
4 & 0.64 to 0.85 & 0.85 & 0.58 \\
5 & 0.85 to 1.07 & 1.07 & 0.69 \\
6 & 1.07 to 1.98 & 1.98 & 0.82 \\
7 & 1.98 to 2.90 & 2.90 & 0.96 \\
8 & 2.90 to 4.91 & 4.91 & 1.11 \\
9 & 4.91 to 6.97 & 6.97 & 1.31 \\
10 & 6.97 to 14.6 & 14.6 & 1.68 \\
11 & 14.6 to 36.5 & 36.5 & 1.88 \\
\hline
\end{tabular}

Table 3 Detailed information about the volumes collected in the sampling system ( ${ }^{1}$ cumulative runoffvolume associated with each container $\left({ }^{1}\right.$ cumulative runoff volume associated with each container, ${ }^{2}$ Supplemetary volume in the $5^{\circ}$ inclined PVC pipe) 
Runoff volumes captured in the containers were collected after each rainfall period for analysis (e.g. the experimental system was emptied), delimitating 15 sampling periods with varying durations and runoff volumes (cf. Table 4).

\begin{tabular}{ccccc}
\hline Period $\mathrm{N}^{\circ}$ & from & to & Rainfall volume $(\mathrm{mm})$ & Samples collected \\
\cline { 1 - 5 } \cline { 3 - 5 } 2 & $19 / 05 / 2014$ & $22 / 05 / 2014$ & 21.8 & 11 \\
3 & $22 / 05 / 2014$ & $27 / 052014$ & 11.8 & 10 \\
4 & $27 / 05 / 2014$ & $04 / 06 / 2014$ & 20.8 & 11 \\
5 & $28 / 06 / 2014$ & $29 / 06 / 2014$ & 12 & 10 \\
6 & $29 / 06 / 2014$ & $06 / 07 / 2014$ & 15.2 & 12 \\
7 & $07 / 07 / 2014$ & $15 / 07 / 2014$ & 78.2 & 12 \\
8 & $19 / 07 / 2014$ & $21 / 07 / 2014$ & 18.0 & 3 \\
9 & $22 / 07 / 2014$ & $25 / 07 / 2014$ & 0.6 & 12 \\
10 & $23 / 07 / 2014$ & $29 / 07 / 2014$ & 29.4 & 11 \\
11 & $02 / 08 / 2014$ & $04 / 08 / 2014$ & 15.4 & 11 \\
12 & $06 / 08 / 2014$ & $10 / 08 / 2014$ & 26.6 & 9 \\
13 & $11 / 08 / 2014$ & $13 / 08 / 2014$ & 12.6 & 11 \\
14 & $14 / 08 / 2014$ & $18 / 08 / 2014$ & 6.6 & 5 \\
15 & $22 / 08 / 2014$ & $28 / 08 / 2014$ & 18.6 & 1.6 \\
\hline
\end{tabular}

Table 4 Sampling periods and corresponding rainfall volumes

The collection system performed satisfactorily for the $1^{\text {st }}$ to the $7^{\text {th }}$ container, after which leakage was sometimes observed until the issue was fixed (periods 11 to 15). For periods 1 to 10 , the first 7 samples are therefore assumed to provide representative concentration values for the first 7 fractions of runoff, whereas a concentration range is derived from samples $\mathrm{n}^{\circ} 7$ to 11 , for the remaining fraction of runoff. Similarly, fractions 1 to 9 are considered as correct for the 5 last periods. Finally, water remaining in the $5^{\circ}$ inclined collection pipe at the end of a sampling period is also collected. This volume is associated with a last fraction of runoff (corresponding volume depends on the amount of water collected in the pipe, as shown in table 4).

\subsection{CHEMiCAL ANALYSIS}

For each experiment, collected samples were acidified with nitric acid to $\mathrm{pH}=1$ and vacuum filtered through $0.45 \mu \mathrm{m}$ cellulose acetate filters. Zinc concentrations were determined using inductively coupled plasma atomic emission spectrometry (ICP-AES, Varian Vista MPX) (detection limit for $\mathrm{Zn}=0.2 \mu \mathrm{g} / \mathrm{l}$ ). $\mathrm{pH}$ and conductivity measurements were additionally performed with a WTW SenTix ${ }^{\circledR}$ 41-3 pH-probe and a $\operatorname{TetraCon}^{\circledR} 325$ conductivity cell.

\section{Modelling METHODOLOGY}

\subsection{THE RUNOFF QUALITY MODEL}

The processes associated with runoff contamination are generally complex and involve numerous environmental factors such as air pollution, human activities (traffic) and meteorological conditions (wind and rainfall characteristics). While some modelling approaches have attempted to account for their effect on stormwater runoff quality (Fallah Shorshani et al., 2015, 2014), parsimonious conceptual models, that simulate pollutant 
loads or concentrations from simple rainfall or runoff data, are often preferred for common applications, as more easy to calibrate and to implement (Freni et al., 2009).

The formulation of many of these conceptual runoff quality models still reflects the processes associated with pollutant accumulation on urban surfaces and their removal during rain events. Although recent findings suggest that the reliability of such formulations should be questioned, given the complexity of the processes involved in stormwater contamination, these have essentially been tested for the replication of suspended solids concentrations in urban runoff (Freni et al., 2009; Kanso et al., 2006, 2005). In the case of zinc emission from roofing materials these models however remain attractive as the formation of corrosion products over metal surfaces can typically be interpreted as an accumulation process (He, 2002). Furthermore, metal (zinc or copper) concentrations have often been shown to exhibit a very distinctive temporal pattern (Förster, 1996; He et al., 2001; Zhang et al., 2002; Zobrist et al., 2000) which can easily be replicated by simple wash-off models.

In this study, a runoff quality model based on the widely used exponential accumulation and wash-off functions (Alley and Smith, 1981; Alley, 1981) is introduced. The following equation is thus adopted for a continuous description of the formation and removal of corrosion products over zinc panels:

$$
\frac{d M_{A C C}(t)}{d t}=D \times\left[M_{L I M}-M_{A C C}(t)\right]-M_{A C C}(t) \times K_{1} \times i(t)^{K_{2}}
$$

Where: $\mathrm{M}_{\mathrm{ACC}}(\mathrm{t})=$ easily removable or soluble corrosion products accumulated over zinc surface $\left[\mathrm{M} \cdot \mathrm{L}^{-2}\right], \mathrm{M}_{\mathrm{LIM}}=$ asymptotic limit of the accumulation model $\left[\mathrm{M} \cdot \mathrm{L}^{-2}\right], \mathrm{D}=$ accumulation coefficient $\left[\mathrm{T}^{-1}\right], \mathrm{i}(\mathrm{t})=$ rainfall intensity $\left[\mathrm{L} . \mathrm{T}^{-1}\right], \mathrm{K}_{1}$ and $\mathrm{K}_{2}=$ wash-off model parameters.

The formation of corrosion products over metal surfaces can reasonably be considered as a slow process as compared to its removal during rain events (Zhang et al., 2002). Hence, the amount of corrosion products $\mathbf{M}_{t}$ washed-off during a time step $\Delta t$, under constant rainfall intensity $i_{t}$ (where subscript $t$ refers to the time step from $t$ to $t+\Delta t$ ) can be obtained from the integration of equation (1) by neglecting the term associated with accumulation:

$$
M_{t}=-\int_{t}^{t+\Delta t} d M_{A C C}=M_{A C C}(t) \times\left[1-\exp \left(-K_{1} \times i_{t}^{K_{2}} \times \Delta t\right)\right]
$$

It can be noted that equation (2) only reflects the removal of a limited storage of loosely adherent or soluble corrosion products during rainfall. Because metal concentrations usually reach an approximately constant nonzero value, after a strong decrease in the first millimetres of runoff (Förster, 1996; He et al., 2001; Schriewer et al., 2008), zinc wash-off cannot solely be described as a source limited process. Previous equation is therefore combined with a transport limited wash-off function so as to replicate the "quasi steady state" behaviour observed after the initial decrease of zinc concentrations. Concentrations computed from this second term can be interpreted as the result of the dissolution of a much larger storage of zinc compounds (infinite) exhibiting a much lower solubility than those associated with the "source limited" term. The general form of the runoff quality model investigated in this study may hence be written as follow: 


$$
C_{t}=\frac{1}{i_{t} \times \Delta t} \times\left(M_{A C C}(t) \times\left[1-\exp \left(-K_{1} \times i_{t}^{K_{2}} \times \Delta t\right)\right]+K_{0} \times i_{t}^{K_{3}} \times \Delta t\right)
$$

Where: $C_{t}=$ concentration in runoff between $t$ to $t+\Delta t, K_{0}$ and $K_{3}=$ parameters for the transport limited component of the runoff quality model. When $\mathrm{K}_{3}=1$, concentrations simulated by the right-hand "transport limited" term remain $\mathrm{K}_{0}$ regardless of rainfall intensities, whereas $\mathrm{K}_{3} \leq 1$ introduces a relation between these "steady state" concentrations and rainfall intensities, replicating dilution effects at larger $\mathrm{i}$ values (the case $\mathrm{K}_{3}=0$ can be interpreted as the volume dilution of a constant "steady state" flux $K_{0} \times \Delta t$ ).

After computing $\mathrm{M}_{\mathrm{t}}$, the amount of easily removable or soluble corrosion products can be updated by subtracting $\mathrm{M}_{\mathrm{t}}$ to the pollutant storage available at $\mathrm{M}_{\mathrm{ACC}}(\mathrm{t})$. Accumulation is finally simulated using equation (1), this time by neglecting the wash-off term, and the amount of corrosion products available at the next time step can be calculated from:

$$
M_{A C C}(t+\Delta t)=\left[M_{A C C}(t)-M_{t}\right] \times \exp (-D \times \Delta t)+M_{L I M} \times[1-\exp (-D \times \Delta t)]
$$

\subsection{MODEL CALIBRATION AND UNCERTAINTY ANALYSIS}

It is today well accepted that the reliability of a model does not solely result from its ability to replicate observations. The fact that different sets of model parameters may produce satisfactorily fit to the calibration data, may indeed result in high parameter and predictive uncertainties (Beven and Binley, 1992; Beven, 1993; Deletic et al., 2012; Dotto et al., 2011). Uncertainty analysis therefore provides opportunities for the selection of reliable and parsimonious models, as it explores the sensitivity to model parameters as well as the confidence in simulation results (Freni et al., 2009).

A Monte-Carlo Markov-Chain (MCMC) sampling method is therefore adopted for the evaluation of the runoff quality model for the in situ experiment. This approach assumes that simulation results, for a set of parameters $\theta$, may be expressed in probabilistic terms by formulating assumptions regarding the structure of residuals between model's outcome $f(\theta)$ and observations $D$. The probability density function of model parameters $P(\theta \mid D)$ can thus be derived from prior knowledge about model parameters $\mathrm{P}(\theta)$ updated by observations $\mathrm{D}$ by application of Bayes theorem:

$$
P(\theta \mid D)=\frac{P(\theta) P(D \mid \theta)}{\int P(D \mid \theta) P(\theta) d \theta}
$$

Where $P(D \mid \theta)$ is the likelihood function $L(D \mid \theta)$ which measures the probability of simulation errors. When $P(\theta)$ is uniform (non-informative), the integral term can be seen as a normalizing constant and $\mathrm{P}(\theta \mid \mathrm{D})$ is proportional to the likelihood $\mathrm{L}(\mathrm{D} \mid \theta)$.

Gaussian likelihood functions $\mathrm{L}(\mathrm{D} \mid \theta)$ have often been adopted, assuming that residuals are independent, homoscedastic and normally distributed. However, such hypotheses are generally unverified and recent results suggest that violation of these assumptions may significantly affect the reliability of uncertainty analyses results 
(Del Giudice et al., 2013; Dotto et al., 2013; Schoups and Vrugt, 2010; Thyer et al., 2009). In this study, an autoregressive AR(1) error model is introduced for a realistic bias description and a "log-sinh" transformation (Del Giudice et al., 2013; Wang et al., 2012) is adopted to reduce the dependence between residuals and model outputs. In the transformed space, the error model can thus be written as:

$$
\begin{gathered}
e_{i}=\rho \times e_{i-1}+\varepsilon_{i} \\
g(y)=\beta \log \left[\sinh \left(\frac{\alpha+y}{\beta}\right)\right]
\end{gathered}
$$

Where: $\mathrm{y}=$ output data (e.g. simulated or measured concentrations) $\mathrm{g}(\mathrm{y})=$ transformed output data, $\rho=$ autocorrelation coefficient, $\mathrm{e}_{\mathrm{i}}=$ residuals between transformed model outputs and transformed observations for the $\mathrm{i}^{\text {th }}$ measurement, $\varepsilon_{\mathrm{i}}=$ stochastic innovations at $\mathrm{i}, \alpha$ and $\beta=$ lower and upper reference output for the log-sinh transformation. (Here, $\rho, \alpha$ and $\beta$ are treated as model parameters during the calibration).

Despite the transformation of output data, the assumption of normally distributed innovations in the error model (Eq. 6) remains inconsistent. Innovations are thus assumed to follow a Student t-distribution with standard deviation $\sigma$ and degrees of freedom $v$, following the approach of Yang et al. (2007). In these conditions, the expression for the likelihood function is:

$$
L(\theta \mid D)=\frac{\Gamma\left(\frac{v+1}{2}\right)}{\Gamma\left(\frac{v}{2}\right)} \frac{\sqrt{1-\rho^{2}}}{\sigma \sqrt{\pi(v-2)}}\left[1+\frac{e_{1}^{2}\left(1-\rho^{2}\right)}{(v-2) \sigma^{2}}\right]^{-\frac{v+1}{2}}\left|\frac{d g}{d y}\right|_{y_{i}} \prod_{i=2}^{n}\left[\frac{\Gamma\left(\frac{v+1}{2}\right)}{\Gamma\left(\frac{v}{2}\right)} \frac{1}{\sigma \sqrt{\pi(v-2)}}\left(1+\frac{\varepsilon_{i}^{2}}{(v-2) \sigma^{2}}\right)^{-\frac{v+1}{2}}\left|\frac{d g}{d y}\right|_{y_{i}}\right]
$$

Where $\mathrm{e}_{1}=$ residuals at the first time step, $\mathrm{n}=$ number of observations, $\varepsilon_{\mathrm{ti}}=$ innovations at the $\mathrm{i}^{\text {th }}$ time-step, $|\mathrm{dg} / \mathrm{dy}|=$ derivative of the $\log$-sinh function, $\Gamma=$ Gamma function. (Note that $\rho$ and $\sigma$ are treated as model parameters and estimated within the Bayesian framework).

Once the likelihood function is specified, the Metropolis Hasting (1970) algorithm can be implemented to generate samples from the posterior probability distribution $\mathrm{P}(\theta \mid \mathrm{D})$, which reflects the uncertainty associated with model parameters. (From a practical perspective, a narrow posterior distribution indicates that a parameter significantly affects model performance, whereas a large dispersion denotes a low sensitivity and a difficult identification of satisfactory parameter values). At each time step, a set of parameter $\theta$ ' is generated from a previously sampled set of parameter $\theta$. Movement from $\theta$ to $\theta^{\prime}$ depends upon a transition probability which is selected to ensure convergence of the sample towards the actual posterior distribution $\mathrm{P}(\theta \mid \mathrm{D})$ (see Chib and Greenberg, 1995 for further details).

In this study, the Metropolis-Hasting algorithm is run for 10 independent Markov chains with 50.000 iterations from a previously identified (e.g. through an initialization run) maximum likelihood estimate. Best fit of the innovations to their theoretical distribution is achieved by setting the degrees of freedom $v$ of the Student $\mathrm{t}$ distribution to 6 (corresponding diagnostic plot are available as supplementary material). Because a concentration range is associated with the fraction of runoff corresponding to the last containers in the collection 
system, this measurement uncertainty is additionally propagated through the calibration algorithm by generating a concentration value within this range (uniform sampling) at each iteration of the Metropolis-Hasting algorithm. The Nash-Sutcliffe (1970) efficiency coefficient (E) is calculated for the simulation results associated with each set of parameters of the posterior distribution and model performance is evaluated from the most likely E value of sampled distribution. Confidence intervals associated with parameter and total predictive uncertainty are finally generated by (1) running the model for 1000 set of parameters sampled from the distribution $\mathrm{P}(\theta \mid \mathrm{D})$ (parameter uncertainty) and (2) propagating the error term shown in equation 6 (total predictive uncertainty). (These intervals reflect the uncertainty associated with simulation results for predictive purposes).

\section{RESULTS AND DISCUSSION}

\subsection{SIMULATED RAINFALL EXPERIMENT}

\subsubsection{Data description}

For each rainfall intensity (i) and antecedent dry period duration $\left(\mathrm{T}_{\mathrm{DRY}}\right)$, zinc concentrations exhibit a similar temporal pattern, with a strong decrease with the first 2 to 3 millimetres from a high initial concentrations to a rather stable value. It can nonetheless be noted that this "steady state" region seems to be reached more quickly for short antecedent dry period durations (especially when comparing the results obtained for $\mathrm{T}_{\mathrm{DRY}}=21$ days to those associated with shorter exposure durations) and, to a lesser extent, for high rainfall intensities (cf. Figure $2 \mathrm{a}$ and $2 \mathrm{~b}$ ). While the cumulative rainfall volume associated with the initial decrease of zinc concentration and the differences observed from an experiment to another could clearly be regarded as limited, it is important to point out that small rain events that do not exceed $5 \mathrm{~mm}$ actually represent a large fraction of the annual rainfall volume in Paris region. The few millimetres differences in the cumulative volume associated with the initial concentration decrease shown in Figure 2a thus remain important as compared to the rainfall volume associated with most rain events.

Fig. 2a

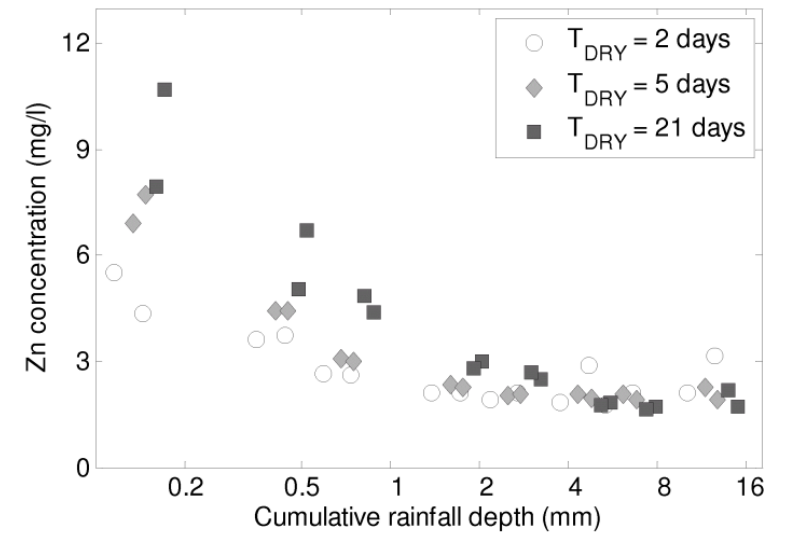

Fig. $2 b$

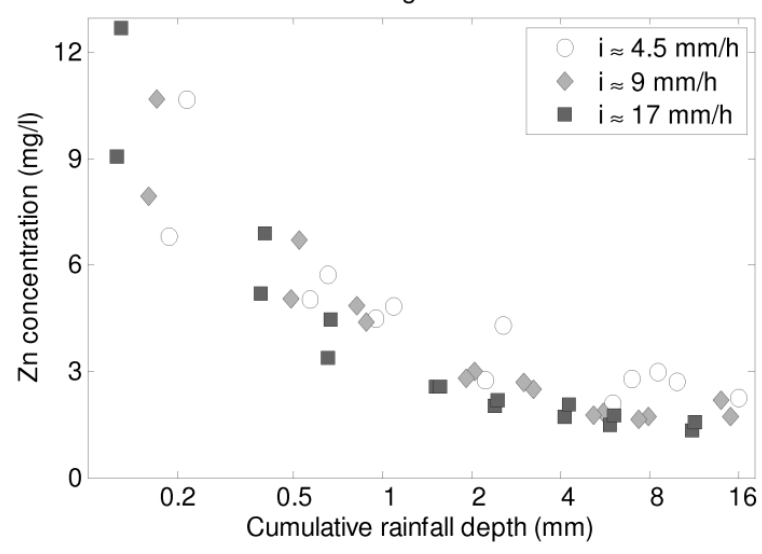

Fig2 Laboratory experiment results - 2a: effect of antecedent dry period for $9 \mathrm{~mm} / \mathrm{h}$ rainfall intensity, $2 \mathrm{~b}$ : effect of rainfall intensity for a 21 days antecedent dry period (Error bars represent the measurements associated with each duplicate) 
Significant variations are observed for $\mathrm{Zn}$ concentrations in the first fraction of runoff $(\mu=7.30 \mathrm{mg} / \mathrm{l}, \sigma=2.56$ $\mathrm{mg} / \mathrm{l})$ which seems to be positively correlated to antecedent dry period duration $\mathrm{T}_{\mathrm{DRY}}\left(\mathrm{R}^{2}=0.46\right.$, $\mathrm{p}$-value $\left.=0.05\right)$, although an outlier is obtained for $\mathrm{T}_{\mathrm{DRY}}=2$ days and $\mathrm{i} \approx 17 \mathrm{~mm} / \mathrm{h}$ (cf. Figure $3 \mathrm{a}$ ). This result is consistent with those of He et al. (2001) who suggested that this dependence could be associated with the formation of corrosion products during non-rainfall periods. By contrast, no correlation is here observed between the concentration in the first samples and rainfall intensity. However, this difference with the results of He et al. (2001) possibly originates from the very low rainfall intensity $(<1 \mathrm{~mm} / \mathrm{h})$ used in their drizzle experiment, for which higher contact time with metal surfaces and very specific runoff conditions are believably achieved (water flowing as droplets).

Steady state concentrations, comprised between 1.1 and $3.1 \mathrm{mg} / \mathrm{l}$, remain quite similar from an experiment to the other. However, $\mathrm{Zn}$ concentration in the last sample seems to be negatively correlated to i (cf. Figure $3 b$, $\mathrm{R}^{2}=$ $0.58, \mathrm{p}$-value $=0.01)$ which may reflect a dilution effect at higher rainfall intensities. This relationship should nonetheless be carefully interpreted as the duration of each experiment is here selected in accordance with rainfall intensity (to achieve the same volume for each experiment). Hence, the increase of concentrations at lower i values might as well be a consequence of a longer exposure to precipitations.
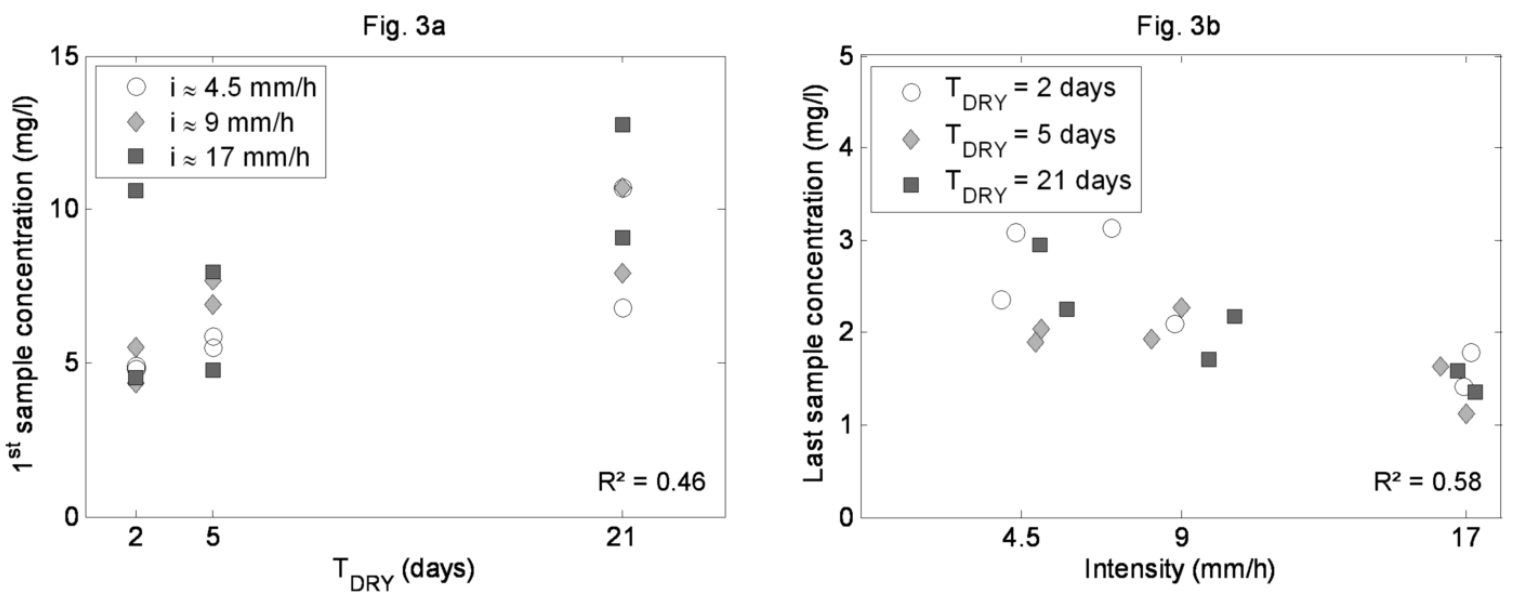

Fig.3 Effect of $\mathrm{T}_{\mathrm{DRY}}$ and rainfall intensity. Relation between 3a: the concentration in the first sample and $\mathrm{T}_{\mathrm{DRY}}$. $3 \mathrm{~b}$ : the concentration in the last sample and rainfall intensity.

\subsubsection{Model fitting}

\subsubsection{Model formulation}

_For the simulated rainfall experiments, the wash-off model (equation 3) is fitted to the data for each of the 18 concentration patterns $\left(3 \mathrm{~T}_{\mathrm{DRY}}\right.$ values $\times 3$ rainfall intensities $\times 2$ replicates) with a simple least square optimization. Because each test is conducted under constant rainfall intensity, model parameter $\mathrm{K}_{2}$ is set to 1 (the dependence between $K_{1}$ and i should therefore be investigated). Given the low variations in the observed steady state concentrations, a constant steady state concentration model is considered, with $\mathrm{K}_{3}=1$. Accumulation is not considered for this application and the initial amount of corrosion products $\mathrm{M}_{\mathrm{ACC}}(\mathrm{t}=0)$ is thus adjusted along with wash-off model parameters $\mathrm{K}_{0}$ and $\mathrm{K}_{1}$. 
The purpose of these adjustments is (1) to determine if the concentration patterns of the simulated rainfall experiment can be approximated by a simple exponential function and (2) to evaluate the differences in fitted parameters from an experiment to the other so as to complement the analysis of the measurements and further investigate the effect of $\mathrm{i}$ or $\mathrm{T}_{\mathrm{DRY}}$ on zinc emission dynamics.

\subsubsection{Modelling results}

The wash-off dynamics simulated from equation (3) satisfactorily describes the variation of zinc concentration monitored for the different experiments $\left(\mathrm{R}^{2}=0.86\right.$ to 0.99$)$. Optimal values for parameters $\mathrm{K}_{0}$ and $\mathrm{K}_{1}$ vary moderately from an experiment to another $\left(\mu=2.0 \mathrm{mg} / 1, \sigma=0.46 \mathrm{mg} / 1\right.$ for $\mathrm{K}_{0}$ and $\mu=2.6, \sigma=0.69$ for $\left.\mathrm{K}_{1}\right)$, whereas important differences are observed for fitted $\mathrm{M}_{\mathrm{ACC}}(\mathrm{t}=0)$ values. Although moderate, the correlation between $\mathrm{M}_{\mathrm{ACC}}(\mathrm{t}=0)$ and $\mathrm{T}_{\mathrm{DRY}}$ remains statistically significant $\left(\mathrm{R}^{2}=0.66\right.$, p-value $\left.<0.01\right)$. The results of these simple model adjustments hence indicate that zinc wash-off can be well described as a source-limited process at the beginning of rainfall periods, and again suggests that the temporal variability of zinc concentrations could be largely driven by the formation of easily soluble corrosion products over zinc surfaces during dry periods (even though the rate of corrosion is believably unsteady and affected by other environmental factors). On the other hand, no relation between $\mathrm{K}_{1}$ and rainfall intensity is observed, and the value of the second wash-off parameter $\mathrm{K}_{2}$ (Eq. 2 and 3) can thus probably be expected to be somewhat close to 1 .

\subsection{IN-SITU EXPERIMENT}

\subsubsection{Data description}

Zinc concentrations in the 150 runoff samples collected from May to September 2014 range between 0.58 and $15.16 \mathrm{mg} / \mathrm{l}(\mu=4.23 \mathrm{mg} / \mathrm{l}, \sigma=2.20 \mathrm{mg} / \mathrm{l})$. Surprisingly, these concentrations are relatively close to those obtained for the simulated rainfall experiment, despite the differences in the age of the zinc panels. As for the simulated rainfall experiment, $\mathrm{pH}$ here remains relatively high and exhibits moderate variations $(\mu=6.7 \sigma=0.4)$.

The evolution of zinc concentrations from the outdoor panel is generally similar to the one observed for the simulated rainfall experiment, starting from relatively high and quickly decreasing concentrations in the first samples (cf. Figure 4.a). As shown in figure 4b, the magnitude of this decrease may, however, significantly vary depending on the sampling period. Besides, concentrations associated with the last runoff fractions do not always stabilize around an approximately constant value like in the simulated rainfall experiment. As shown in figure $4 \mathrm{~b}$, an increase of zinc concentrations can indeed be observed for some rainfall periods after the initial decrease of concentrations with the first millimetres of runoff. Such variations are nonetheless not easily interpretable in the case of average concentrations under unsteady rainfall intensities (as one runoff fraction may actually cover very different durations, encompass highly variable rainfall conditions or even be associated with several distinct rain events separated by relatively long dry periods). 
Fig. $4 a$

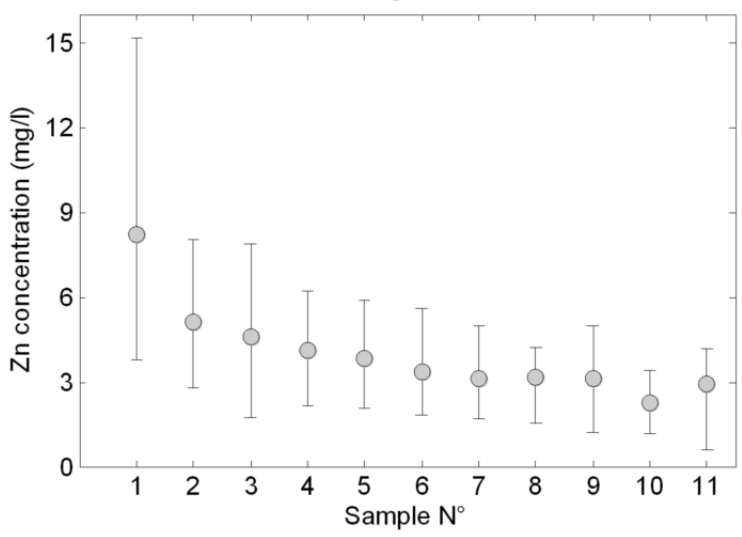

Fig. $4 b$

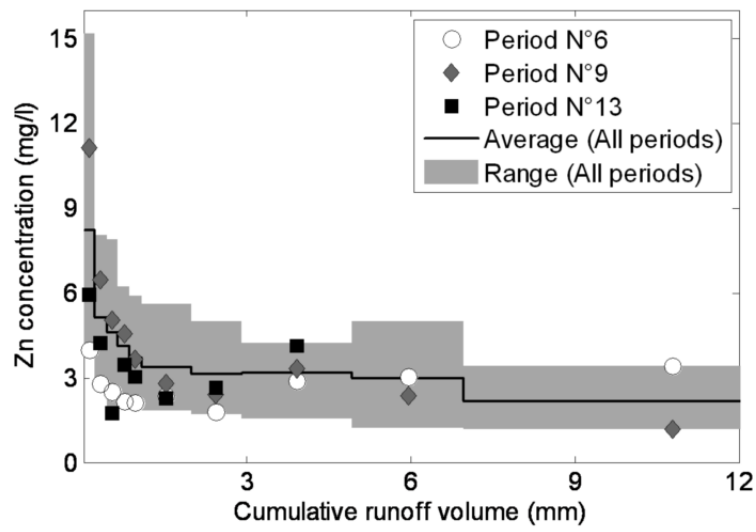

Fig4 In-situ experiment results - 4a: zinc concentration the different runoff fractions (circles represent average values over the 15 rainfall periods and minimum and maximum values are displayed as error bars), 4b. Zinc concentrations as a function of cumulative runoff volume (example for periods 6 and 9)

Again, the overall evolution of zinc concentrations (as a function of the runoff volume) is consistent with previous findings, although higher concentration values have generally been reported. In the experiment conducted by Schriewer et al. (2008), concentrations ranging from 6 to $20 \mathrm{mg} / \mathrm{l}$ were measured in the first fractions of runoff, with "steady-state" concentrations between 3 and $8 \mathrm{mg} / \mathrm{l}$. These differences are however not completely surprising as an older metal surface was considered (14 year old zinc roof). Steady state concentrations are also lower than those obtained by He et al. (2001) for new zinc panels, but this result is quite expectable as more acidic $\mathrm{pH}$ values (3.8 to 4.8 ) were considered.

\subsubsection{Runoff quality model evaluation}

The performance of the accumulation and wash-off model (equations 3 and 4) is evaluated against in-situ measurements, using the calibration and uncertainty analysis method described in the section 3.2. The model is implemented at a 1-min time-step to replicate zinc concentrations in runoff from precipitation records (continuous modelling from May to September 2014) and average simulated concentration values are derived for the runoff fractions corresponding to the measurements.

\subsubsection{Application of the model with $K_{3}=1$}

The model is first evaluated under the simplifying hypothesis that "steady state" concentrations remain constant, regardless of rainfall intensities, i.e. assuming $\mathrm{K}_{3}=1$.

The performance of the model appears quite satisfactory, with a 0.61 Nash-Sutcliffe efficiency coefficient for the maximum of posterior distribution (cf. Figure 5). The model however does not systematically succeed in replicating zinc measurements (cf. Figure 6a) and thus exhibits a high predictive uncertainty, despite a decent overall performance. Interestingly, while the contribution of parameter uncertainty remains relatively moderate, coverage intervals tend to be wider for high concentration values, which suggest that larger uncertainties might be associated with accumulation parameters $\left(\mathrm{M}_{\mathrm{LIM}}\right.$ and $\left.\mathrm{D}_{\mathrm{ACC}}\right)$ controlling the magnitude of concentrations at the beginning of each period. 

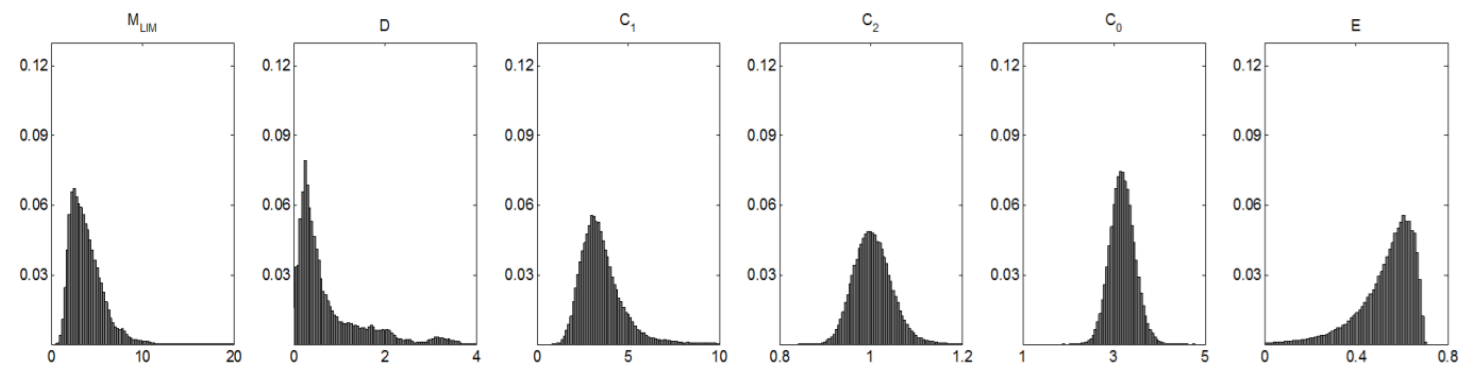

Fig5 Posterior probability distribution of model parameters and Nash-Sutcliffe efficiency coefficient E (original model formulation)

Posterior distributions computed from the Metropolis-Hasting algorithm (cf. Figure 5) indicate that optimal values could be identified for all model parameters (unimodal distributions) and suggest that the calibration was not significantly impeded by equifinality problems (discussion on this concept can be found Beven and Binley, 1992; Beven, 1993). Posterior probability distributions however exhibit a relatively important dispersion for all model parameters (which tends to be more pronounced for accumulation parameters $\mathrm{M}_{\mathrm{LIM}}$ and $\mathrm{D}_{\mathrm{ACC}}$ ).
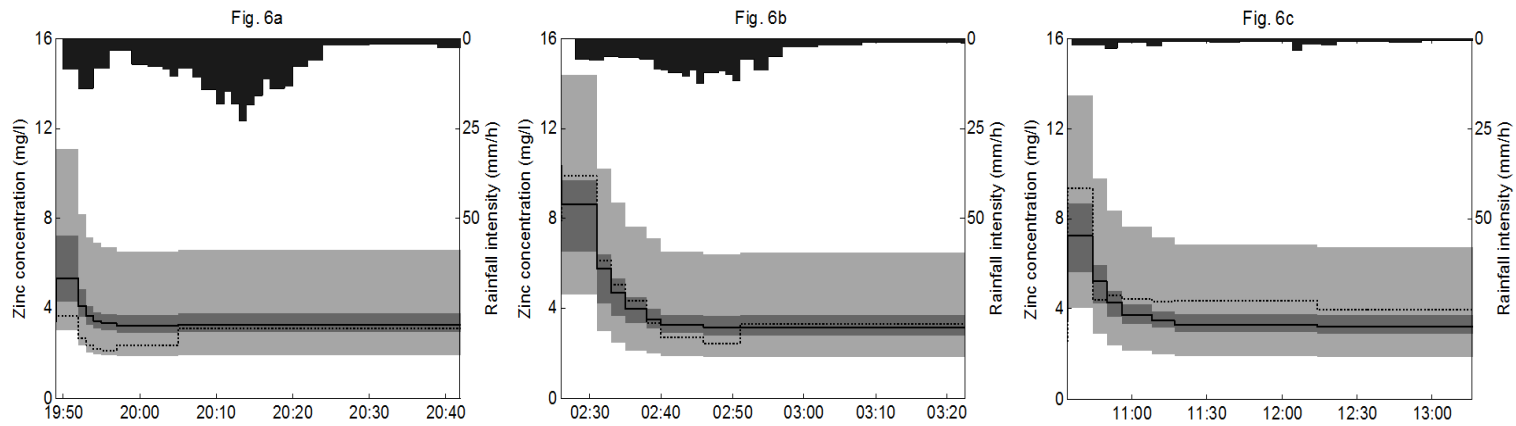

Fig.6 Simulation results (original model formulation) - 6a: Period $n^{\circ} 6,6 b$ : Period $n^{\circ} 9,6 c$ : Period $n^{\circ} 13$ (Solid black line $=$ simulated concentrations $($ maximum of likelihood), dashed line $=$ measurements, light shaded area $=$ $5-95 \%$ total uncertainty coverage, dark shaded area $=5-95 \%$ parameter uncertainty coverage, black area $=$ rainfall intensity)

The uncertainty associated with accumulation rate $\mathrm{D}_{\mathrm{ACC}}$ appears to be particularly high, with values ranging from 0.05 to more than 4 days $^{-1}$. While a relatively low optimal accumulation rate $\left(0.27\right.$ days $\left.{ }^{-1}\right)$ can clearly be identified from the posterior distribution, the dispersion towards higher values of $\mathrm{D}_{\mathrm{ACC}}$, for which accumulation is mostly instantaneous, casts doubts on the validity of the accumulation model (Kanso et al., 2005; Sage et al., 2015). The shape of the distribution nevertheless indicates that the model remains sensitive to accumulation parameters, which confirms that formation of corrosion products during dry period could partly govern the variability of zinc concentrations in runoff. However, more than for the simulated rainfall experiment, the dependence between the concentrations in the first sample of each period as a function of $\mathrm{T}_{\mathrm{DRY}}$ here remains unclear (cf. Figure 7). Results therefore suggest that the variability of zinc concentrations at the beginning of rain events cannot be solely explained by the model (cf. Figure 6a), which was expectable as corrosion depends on various environmental factors such as temperature, relative humidity or atmospheric pollution (LeuenbergerMinger et al., 2002; Schriewer et al., 2008). 


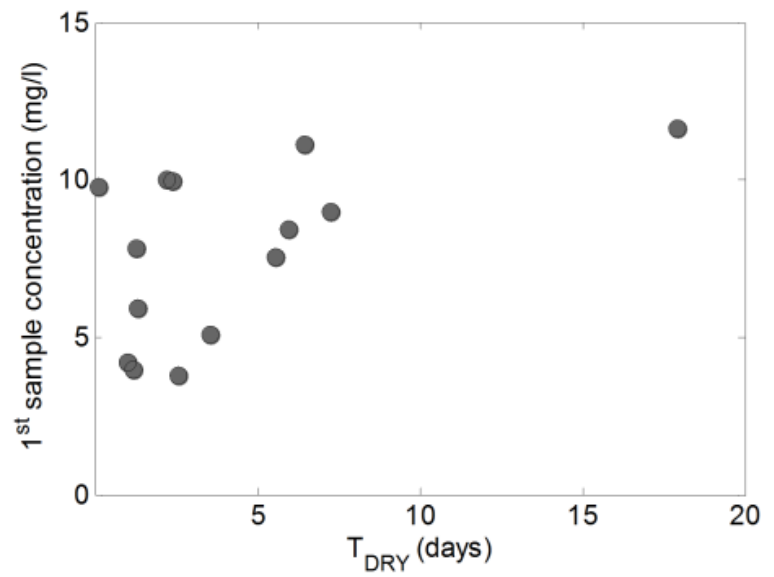

Fig7 Relation between the concentration in the first sample of each rainfall period of the in-situ experiment and antecedent dry period duration $\mathrm{T}_{\mathrm{DRY}}$.

As compared to accumulation parameters, the model clearly displays a high sensitivity to $\mathrm{K}_{0}, \mathrm{~K}_{1}$ and $\mathrm{K}_{2}$ (low dispersion of model parameters in figure 6) and optimal values for these parameters $\left(\mathrm{K}_{0}=3.12 \mathrm{mg} / \mathrm{l}, \mathrm{K}_{1}=3.08\right.$, $\mathrm{K}_{2}=1.01$ ) are relatively similar to those obtained for the simulated rainfall experiment (differences believably result from the age of the material or exposure conditions). Posterior probability distribution for $\mathrm{K}_{2}$ indicates that this parameter remains close to 1 , and once more suggests that rainfall intensity does not significantly affect the removal of corrosion products at the beginning of a rain event. Furthermore, a correlation between $K_{1}$ and $K_{2}\left(R^{2}\right.$ $=0.28$ ) is evidenced during calibration, which supports the idea that deviations of $K_{2}$ from unity are not completely behavioural and call for a simplification of the runoff quality model with $\mathrm{K}_{2}=1$.

Because $\mathrm{K}_{2}$ does not significantly differ from 1 , the amount of water needed to dissolve the majority of the corrosion products can be directly estimated from $\mathrm{K}_{1}$ : according to calibration results, $99 \%$ of accumulated loads are here washed-off after 0.8 to $2.0 \mathrm{~mm}$ of runoff (based on the $5^{\text {th }}$ and $95^{\text {th }}$ percentile of the posterior distribution for $\mathrm{K}_{1}$ ), which is in good agreement with the results presented in figure 2 . In the case of small rainfall events (less than $5 \mathrm{~mm}$ ), this early fraction of runoff may therefore significantly contribute to the overall load discharged to surface waters or sewer systems. Concentration time-series simulated for 10.000 sets of parameters sampled from the posterior distribution $\mathrm{P}(\theta \mid \mathrm{D})$, indicate that the load generated by both the source and the transport limited component of equation 3 during these first millimetres of rainfall (computed as the amount of precipitations needed to remove $99 \%$ of accumulated loads) could for instance represent between 18 and $55 \%$ ( $5^{\text {th }}$ and $95^{\text {th }}$ percentiles) of the total amount of zinc dissolved for the 5 month period considered in the in-situ experiment. The implementation of stormwater source-control systems retaining the contamination associated with the first millimetres of runoff prior to the discharge to conveyance systems (where this concentration decrease is likely to be attenuated) could hence be particularly relevant, providing the opportunity to manage significant amount of pollutants through the capture of relatively small rainfall volumes. The simulation results obtained for the 10.000 samples of the posterior distribution of model parameters nonetheless reveal that the load generated by the source-limited component of equation 3 (e.g. without taking into account the load simulated by the transport limited one) represents, for the same 5 month period, a much smaller proportion of the total zinc discharge (between 5 to $16 \%$, for the $5^{\text {th }}$ and $95^{\text {th }}$ percentiles), indicating that large 
fraction of the load washed-off at early stages of runoff is in fact associated with constant concentration term of equation 3. Hence, the benefits associated with the interception of the first millimetres of runoff do not solely result from variability of zinc concentrations and may also be largely explained by the contribution of small rainfall events to the overall rainfall volume.

Regarding $\mathrm{K}_{0}$, despite a high sensitivity, uncertainty associated with this parameter remains important, with values ranging from 2.7 to $3.9 \mathrm{mg} / \mathrm{l}$ for the $5^{\text {th }}$ and $95^{\text {th }}$ percentiles of sampled distribution. This uncertainty believably reflects the inability of the model to replicate the fluctuations of zinc concentrations after corrosion products have been removed (cf. Figure 5). It can however be noticed from Figure 6 that the fluctuations in $\mathrm{Zn}$ concentration from one period to another remain limited, despite significant differences in rainfall intensities after the first millimetres of runoff.

\subsubsection{Application of the model with $K_{3} \neq 1$ and $K_{2}=1$}

Based on previous modelling results, a different model parameterization is tested. The "source-limited" component of equation 3 is simplified by setting $\mathrm{K}_{2}=1$, whereas a dependence between the concentrations simulated by the transport limited term and rainfall intensities is introduced $\left(K_{3} \neq 1\right)$ in order to determine if the description of zinc concentration fluctuations within the steady state period can be improved.

As compared to previous application, modelling results show a slight increase of the Nash-Sutcliffe efficiency coefficient, from $\mathrm{E}=0.61$ to 0.67 for the maximum of posterior distribution (and $\mathrm{E}=0.70$ to 0.72 for the highest value of sampled distribution). Regarding the likelihood function (Eq. 8), which assigns more weight to lower and intermediate concentration values (as opposed to the Nash Sutcliffe criterion which is a least square objective function), a significant improvement is also observed, with log-likelihood (logarithm of the likelihood) rising from -19.75 to -15.5 for the reformulated wash-off equation.

This increase of the likelihood is accompanied by a decrease of parameter uncertainty, with substantially lower dispersion of posterior probability distributions for some parameters (cf. Figure 8). The reduction of calibration uncertainty associated with model reformulation is particularly visible for accumulation parameter D. As compared to the one generated for initial application of the runoff quality model (cf. Figure 5), posterior distribution indeed here exhibits a sharper peak (again, $\mathrm{D}=0.25$ for the maximum of likelihood), and no longer stretches out to very fast accumulation rates. For the optimal D value, two weeks are needed to reach $97 \%$ of the maximum of easily removable storage $\mathrm{M}_{\mathrm{LIM}}$, which is again consistent with the simulated rainfall experiment. Calibration results therefore support previous hypotheses regarding the formation of corrosion products during dry periods and once more suggest that $\mathrm{T}_{\mathrm{DRY}}$ may be a relevant predictor of zinc concentrations in the first millimetres of runoff. From figure 8, it can however be noted that, while the uncertainty associated with D is significantly reduced for the reformulated runoff quality, posterior distribution of $\mathrm{M}_{\mathrm{LIM}}$ remains relatively unchanged. As a matter of fact, the negative correlation between $D$ and $M_{\text {LIM }}\left(R^{2}=0.44\right.$, also detected for the initial model) indicates that the magnitude of simulated concentrations may often be driven by $M_{\text {LIM }} \times D$. Hence, because the posterior distribution of model parameters include low D values, the model no longer produces asymptotic accumulation for some configurations $\left(a_{\mathrm{LIM}} \times \exp (-\mathrm{D} \times \Delta \mathrm{t}) \approx-\mathrm{M}_{\mathrm{LIM}} \times \mathrm{D} \times \Delta \mathrm{t}\right.$ when $\mathrm{D}$ is small). Such result is not surprising given the weak relation between the concentration at the beginning of a rainfall period 
and $\mathrm{T}_{\mathrm{DRY}}$ (cf. Figure 7). Nonetheless, further simplification to a constant rate accumulation model is believably not desirable, as the simulated rainfall experiment rather suggests that concentrations in the first millimetres of runoff are asymptotically related to $\mathrm{T}_{\mathrm{DRY}}$.
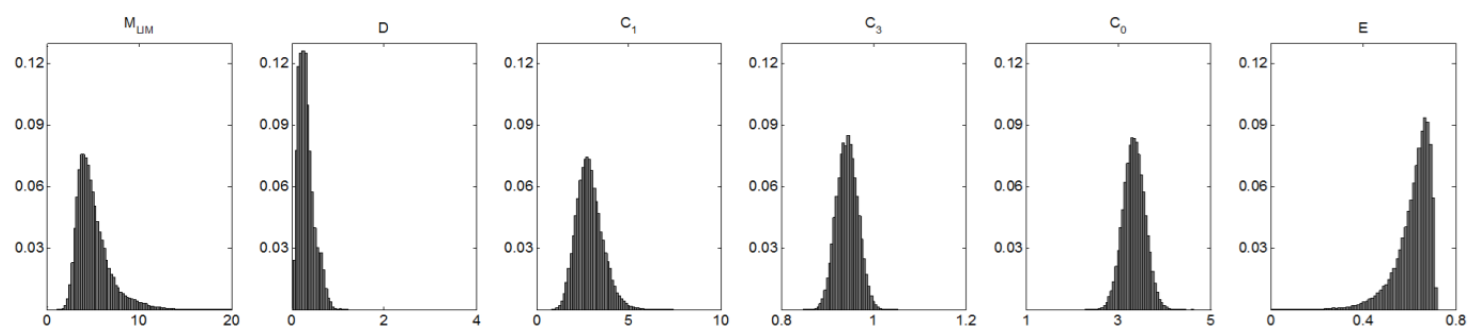

Fig.8 Posterior probability distribution of parameters (reformulated runoff quality model)

Calibration results could at first glance indicate that the introduction of dependence between "steady state" zinc concentrations and rainfall intensity (controlled by parameter $\mathrm{K}_{3}$ ) in the reformulated model is relevant. Posterior probability distribution for $\mathrm{K}_{3}$ indeed exhibits a relatively low dispersion (cf. Figure 8) and no correlation with other parameters could be observed, which suggests that this parameter is behavioural. Uncertainty analysis additionally reveals that this parameter can be expected to remain less than unity (exceeded for the $99^{\text {th }}$ percentile of sampled distribution), and hence produces a decrease of zinc concentrations at higher rainfall intensities for most configurations of the posterior probability distribution. Nonetheless, because $\mathrm{K}_{3}$ generally remains larger than 0.90 (most likely value $=0.94)$, this parameter only produces slight fluctuations of the steady state concentrations ( $20 \%$ difference between 0.5 and $20 \mathrm{~mm} / \mathrm{h}$ for $\mathrm{K}_{3}=0.94$ ). While this very moderate effect of rainfall intensities is consistent with the results of the simulated rainfall experiment, the little reduction of the uncertainty regarding $\mathrm{K}_{0}$, as well as the very limited improvement of model performance at lower concentration values (cf. Figure 9), suggest that the model remains unable to capture all the variability of zinc concentrations after the first millimetres of runoff. (The uncertainty associated with the concentrations measured for the last fractions of runoff probably had a knock-on effect on the calibration procedure and believably explains the relatively large uncertainty associated with $\mathrm{K}_{0}$ ).
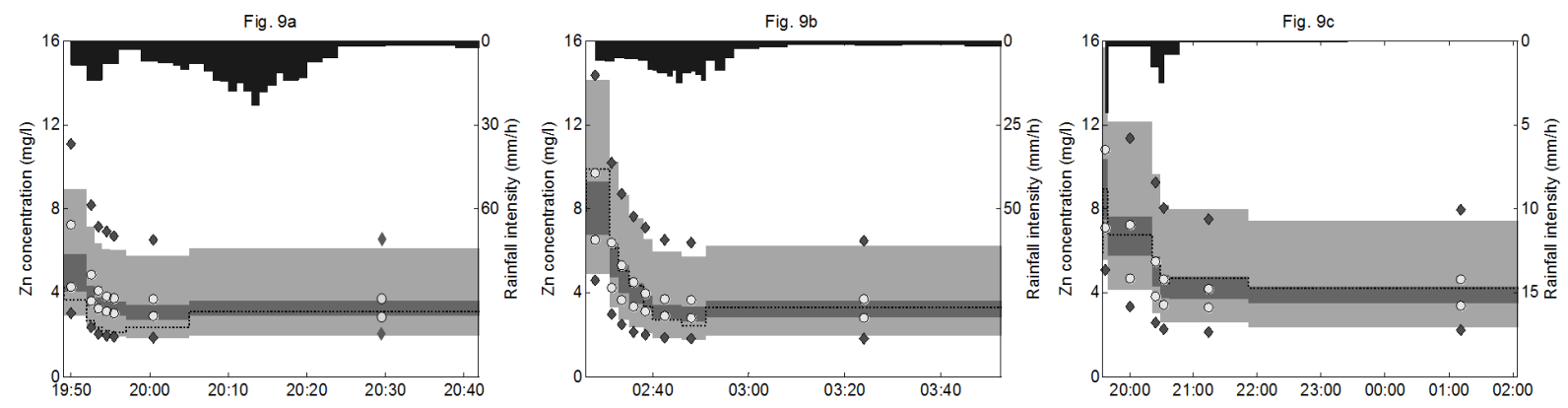

Fig.9 Simulation results (reformulated runoff quality model) - 9a: Period $n^{\circ} 6,9 b$ : Period $n^{\circ} 9,9 c:$ Period $n^{\circ} 14$,

(dashed line $=$ measurements, light shaded area $/$ diamonds $=5-95 \%$ total uncertainty coverage for the reformulated/initial model, dark shaded area/circles $=5-95 \%$ parameter uncertainty coverage the reformulated/initial model, black area $=$ rainfall intensity) 
Previous findings therefore indicate that, although the modified runoff quality model might be preferred over the initial formulation (as it results in a reduction of parameter uncertainty), further simplification of the wash-off equation with $\mathrm{K}_{2}=\mathrm{K}_{3}=1$ could as well be considered (as the reformulation only produces a slight improvement of model performance). While both simulated rainfall experiment and calibration support the adoption of the asymptotic accumulation model (Eq. 1), previous literature results may cast doubts on its applicability (Schriewer et al., 2008), and the poor representation of zinc concentrations for some sampling periods could thus partly result from model's inability to capture all the variability associated with the corrosion process. However, large predictive uncertainties and modest performance is a trait of many runoff quality models (Dotto et al., 2011; Kanso et al., 2006; Vezzaro and Mikkelsen, 2012), and comparison to previous studies suggest that the model presented here is in fact fairly satisfactory. While such conceptual models have often been found to poorly represent reality for large catchments or road surfaces, this study indeed suggests that commonly used model structures could be probably adapted and implemented to simulate the temporal variability of zinc concentrations in runoff. Besides, the ability of the model to replicate zinc concentrations solely from precipitation data remains surprisingly good given the complexity of zinc runoff and corrosion processes, which potentially involve numerous other environmental factors such as rainfall composition, temperature, moisture conditions or air pollution (Bertling et al., 2006; Leuenberger-Minger et al., 2002; Reiss et al., 2004). It is however important to acknowledge that, in this study, the averaging of zinc concentrations in the sampling system after the first millimetres of runoff (cf. 2.2) necessarily dissimulates some of the variability of zinc concentrations. Further research is thus believably needed to improve the description of zinc runoff process.

\section{CONCLUSION AND PERSPECTIVES}

Two distinct experiments were conducted to explore the influence of rainfall intensity and dry period duration on the variability of zinc concentrations from small zinc panels, combining a simulated rainfall approach and in-situ measurements under real weather conditions. After a simple analysis of concentration patterns obtained for the simulated rainfall experiment, a generic runoff quality model was introduced, assuming that the variability of zinc concentrations principally results from the accumulation and the removal of corrosion products over zinc surfaces. The ability of the model to replicate zinc concentrations from the in-situ experiment was investigated for two alternate formulations, allowing for a discussion on the factors controlling the variability of zinc runoff. Calibration and uncertainty analysis were performed using a Markov Chain Monte Carlo sampling method, accounting for both the non-normality and the autocorrelation of the residuals. The results can be summarized as follow:

- Similar concentration patterns were obtained for both experiments, with relatively high (4 to $15 \mathrm{mg} / \mathrm{l}$ ) and quickly decreasing concentrations in the first millimetres of runoff ( 0.5 to $2 \mathrm{~mm}$ ), stabilizing around lower values (1.5 to $5 \mathrm{mg} / \mathrm{l})$ with moderate fluctuations in the remaining fraction of runoff. This observation is consistent with previous studies and presumably reflects the "source limited" nature zinc wash-off at the beginning of a rain event, as a result of the removal of highly soluble corrosion products. For the simulated rainfall experiment, such behaviour was satisfactorily approximated by a first order decay equation. 
- The laboratory experiment evidenced an increase of zinc concentrations in the first millimetres of runoff for longer dry period durations. This dependence was however less visible for the in-situ experiment. While the model generally simulates fairly well the evolution of zinc concentrations in runoff, the lower performance observed for some rainfall periods suggests that many environmental factors (such as air pollution, relative humidity, temperature...) actually govern the formation of corrosion products over zinc surfaces which cannot be solely explained by dry weather duration. Further investigation of the corrosion process at short timescales, during both wet and dry periods, is thus probably needed to better replicate the variability of zinc concentrations and to account for the influence of these environmental factors on zinc emission dynamics.

- Regarding rainfall intensity, neither of the two experiments could evidence an impact of rainfall intensity at early stages of runoff, suggesting that the removal of corrosion products is neither influenced by mechanical forces (as a result of higher intensities), nor increased contact times of rainwater (as a result of lower intensities). Conversely, both experiment tend to indicate that lower rainfall intensities could result in a slight increase of zinc concentrations for the remaining fraction of runoff (e.g. after the initial decrease of zinc concentrations).

- The performance of the runoff quality model was generally satisfactory, despite a relatively high predictive uncertainty, indicating that the overall emission dynamic of zinc could be approximated from very simple conceptual equations using rainfall measurements as the sole model input. The model could therefore be adopted to generate long zinc concentrations time-series, exhibiting a realistic inter- and intra-event variability, differing from those traditionally considered in runoff quality modelling (essentially focusing on suspended solids) and support the design of efficient stormwater control source-control devices. Besides, because zinc concentrations in runoff exceeds EQS by several order of magnitude, the model presented in this study could as well be part of a more integrated modelling framework and be associated with other environmental models so as to assess the effect of stormwater discharge on receiving waters.

- The strong decrease of zinc concentrations observed at beginning of each rainfall period suggests that managing the first millimetres of runoff could result in a significant reduction of the amount of zinc discharged to surface waters or sewer systems. Further investigation is however needed (1) to clarify the importance of the inter- or intra-event variability of zinc concentrations for the design of sourcecontrol system and (2) to specify relevant stormwater capture targets. In this context, the model presented in this study believably offers opportunities for a better understanding of the benefits associated with the interception of the first millimetres of runoff.

- This study finally illustrates the possibilities offered by formal Bayesian methods for the development and the evaluation of stormwater runoff quality models. In this example, careful selection of the error model and the likelihood function allowed for a rigorous assessment of parameter uncertainty, which appeared as a relevant tool for the identification of the most suitable model structure. 


\section{ACKNOWLEDGEMENT}

This research has been carried out under the OPUR research program. The authors gratefully acknowledge the Seine-Normandy Water Agency, Val-de-Marne Departmental Council, Seine-Saint-Denis Departmental Council, Hauts-de-Seine Departmental Council, City of Paris, and the Interdepartmental Association for Sewerage Services in the Paris Metropolitan Area (SIAAP), and the French Ministry of Ecology Sustainable Development and Energy for financial support. The authors additionally acknowledge use of the installations of the Scientific and Technical Centre for Building (CSTB).

\section{REFERENCES}

Ahiablame, L.M., Engel, B.A., Chaubey, I., 2012. Effectiveness of Low Impact Development Practices: Literature Review and Suggestions for Future Research. Water, Air, Soil Pollut. 223, 4253-4273. doi:10.1007/s11270-012-1189-2

Alley, W.M., 1981. Estimation of impervious-area Washoff Parameters. Water Resour. Res. doi:10.1029/WR017i004p01161

Alley, W.M., Smith, P.E., 1981. Estimation of accumulation parameters for urban runoff quality modeling. Water Resour. Res. doi:10.1029/WR017i006p01657

Athanasiadis, K., Horn, H., Helmreich, B., 2010. A field study on the first flush effect of copper roof runoff. Corros. Sci. 52, 21-29. doi:http://dx.doi.org/10.1016/j.corsci.2009.08.048

Bertling, S., Odnevall Wallinder, I., Leygraf, C., Berggren Kleja, D., 2006. Occurrence and fate of corrosioninduced zinc in runoff water from external structures. Sci. Total Environ. 367, 908-923. doi:10.1016/j.scitotenv.2006.01.008

Beven, K., 1993. Prophecy, reality and uncertainty in distributed hydrological modelling. Adv. Water Resour. 16, 41-51. doi:http://dx.doi.org/10.1016/0309-1708(93)90028-E

Beven, K., Binley, A., 1992. The future of distributed models: Model calibration and uncertainty prediction. Hydrol. Process. 6, 279-298. doi:10.1002/hyp.3360060305

Bielmyer, G., Arnold, W.R., Tomasso, J., Isely, J., Klaine, S., 2012. Effects of roof and rainwater characteristics on copper concentrations in roof runoff. Environ. Monit. Assess. 184, 2797-2804. doi:10.1007/s10661011-2152-1

Bressy, A., 2010. Flux de micropolluants dans les eaux de ruissellement urbaines. Effets de différents modes de gestion des eaux pluviales. Université Paris Est.

Bressy, A., Gromaire, M.C., Lorgeoux, C., Saad, M., Leroy, F., Chebbo, G., 2014. Efficiency of source control systems for reducing runoff pollutant loads: Feedback on experimental catchments within Paris conurbation. Water Res. 57, 234-246. doi:10.1016/j.watres.2014.03.040

Bressy, A., Gromaire, M.C., Lorgeoux, C., Saad, M., Leroy, F., Chebbo, G., 2012. Towards the determination of an optimal scale for stormwater quality management: Micropollutants in a small residential catchment. Water Res. 46, 6799-6810. doi:10.1016/j.watres.2011.12.017 
Chib, S., Greenberg, E., 1995. Understanding the Metropolis-Hastings algorithm. J. Am. Stat. Assoc. 49, 327335. doi: $10.2307 / 2684568$

Del Giudice, D., Honti, M., Scheidegger, A., Albert, C., Reichert, P., Rieckermann, J., 2013. Improving uncertainty estimation in urban hydrological modeling by statistically describing bias. Hydrol. Earth Syst. Sci. 17, 4209-4225. doi:10.5194/hess-17-4209-2013

Deletic, A., Dotto, C.B.S., McCarthy, D.T., Kleidorfer, M., Freni, G., Mannina, G., Uhl, M., Henrichs, M., Fletcher, T.D., Rauch, W., Bertrand-Krajewski, J.L., Tait, S., 2012. Assessing uncertainties in urban drainage models. Phys. Chem. Earth 42-44, 3-10. doi:10.1016/j.pce.2011.04.007

Dotto, C.B.S., Deletic, A., McCarthy, D.T., 2013. Uncertainty analysis in urban drainage modelling: should we break our back for normally distributed residuals? Water Sci. Technol. 68, 1271-9. doi:10.2166/wst.2013.360.

Dotto, C.B.S., Kleidorfer, M., Deletic, A., Rauch, W., McCarthy, D.T., Fletcher, T.D., 2011. Performance and sensitivity analysis of stormwater models using a Bayesian approach and long-term high resolution data. Environ. Model. Softw. 26, 1225-1239. doi:10.1016/j.envsoft.2011.03.013

Fallah Shorshani, M., André, M., Bonhomme, C., Seigneur, C., 2015. Modelling chain for the effect of road traffic on air and water quality: Techniques, current status and future prospects. Environ. Model. Softw. 64, 102-123. doi:http://dx.doi.org/10.1016/j.envsoft.2014.11.020

Fallah Shorshani, M., Bonhomme, C., Petrucci, G., André, M., Seigneur, C., 2014. Road traffic impact on urban water quality: A step towards integrated traffic, air and stormwater modelling. Environ. Sci. Pollut. Res. 21, 5297-5310. doi:10.1007/s11356-013-2370-х

Förster, J., 1996. Patterns of roof runoff contamination and their potential implications on practice and regulation of treatment and local infiltration, in: Water Science and Technology. pp. 39-48. doi:10.1016/02731223(96)00329-0

Freni, G., Mannina, G., Viviani, G., 2009. Urban runoff modelling uncertainty: Comparison among Bayesian and pseudo-Bayesian methods. Environ. Model. Softw. 24, 1100-1111. doi:10.1016/j.envsoft.2009.03.003

Gnecco, I., Berretta, C., Lanza, L.G., La Barbera, P., 2005. Storm water pollution in the urban environment of Genoa, Italy. Atmos. Res. 77, 60-73. doi:10.1016/j.atmosres.2004.10.017

Gromaire, M., Robert-Sainte, P., Bressy, A., Saad, M., De Gouvello, B., Chebbo, G., 2011. Zn and Pb emissions from roofing materials--modelling and mass balance attempt at the scale of a small urban catchment. Water Sci. Technol. 63.

Gromaire, M.C., Garnaud, S., Saad, M., Chebbo, G., 2001. Contribution of different sources to the pollution of wet weather flows in combined sewers. Water Res. 35, 521-533. doi:http://dx.doi.org/10.1016/S00431354(00)00261-X

Gromaire, M.C., Van de Voorde, A., Lorgeoux, C., Chebbo, G., 2015. Benzalkonium runoff from roofs treated with biocide products - In situ pilot-scale study. Water Res. 81, 279-287. doi:http://dx.doi.org/10.1016/j.watres.2015.05.060

Hasting, W.K., 1970. Monte Carlo sampling methods using Markov chains and their applications. Biometrika 
57, 97-109. doi:10.1093/biomet/57.1.97

He, W., 2002. Atmospheric Corrosion and Runoff Processes on Copper and Zinc as Roofing Materials (Ph.D.

Thesis). Royal Institute of Technology, Stockholm, Sweden.

He, W., Odnevall Wallinder, I., Leygraf, C., 2001. A laboratory study of copper and zinc runoff during first flush and steady-state conditions. Corros. Sci. doi:10.1016/S0010-938X(00)00066-4

Kanso, A., Chebbo, G., Tassin, B., 2006. Application of MCMC-GSA model calibration method to urban runoff quality modeling. Reliab. Eng. Syst. Saf. 91, 1398-1405. doi:10.1016/j.ress.2005.11.051

Kanso, A., Tassin, B., Chebbo, G., 2005. A benchmark methodology for managing uncertainties in urban runoff quality models. Water Sci. Technol. 51, 163-170.

Karlén, C., Odnevall Wallinder, I., Heijerick, D., Leygraf, C., Janssen, C.R., 2001. Runoff rates and ecotoxicity of zinc induced by atmospheric corrosion. Sci. Total Environ. 277, 169-180. doi:10.1016/S00489697(00)00872-X

Lee, J.G., Selvakumar, A., Alvi, K., Riverson, J., Zhen, J.X., Shoemaker, L., Lai, F., 2012. A watershed-scale design optimization model for stormwater best management practices. Environ. Model. Softw. 37, 6-18. doi:http://dx.doi.org/10.1016/j.envsoft.2012.04.011

Leuenberger-Minger, A.U., Buchmann, B., Faller, M., Richner, P., Zöbeli, M., 2002. Dose-response functions for weathering steel, copper and zinc obtained from a four-year exposure programme in Switzerland. Corros. Sci. 44, 675-687. doi:10.1016/S0010-938X(01)00097-X

Nash, J.E., Sutcliffe, J.V., 1970. River flow forecasting through conceptual models part I-A discussion of principles. J. Hydrol. 10, 282-290. doi:10.1016/0022-1694(70)90255-6

Odnevall Wallinder, I., Leygraf, C., Karlén, C., Heijerick, D., Janssen, C.R., 2001. Atmospheric corrosion of zinc-based materials: Runoff rates, chemical speciation and ecotoxicity effects. Corros. Sci. 43, 809-816. doi:10.1016/S0010-938X(00)00136-0

Odnevall Wallinder, I., Verbiest, P., He, W., Leygraf, C., 1998. The influence of patina age and pollutant levels on the runoff rate of zinc from roofing materials. Corros. Sci. 40, 1977-1982. doi:10.1016/S0010938X(98)00131-0

Persson, D., Kucera, V., 2001. Release of Metals from Buildings, Constructions and Products during Atmospheric Exposure in Stockholm. Water, Air, Soil Pollut. 1, 133-150. doi:10.1023/A:1017556105259

Reiss, D., Rihm, B., Thöni, C., Faller, M., 2004. Mapping Stock at Risk and Release of Zinc and Copper in Switzerland-Dose Response Functions for Runoff Rates derived from Corrosion Rate Data. Water, Air, Soil Pollut. 159, 101-113. doi:10.1023/B:WATE.0000049163.18416.ec

Robert-Sainte, P., 2009. Contribution des matériaux de couverture à la contamination métallique des eaux de ruissellement [Contribution of roofing materials to the metal contamination of runoff]. Université Paris-Est (France), Paris, France.

Robert-Sainte, P., Gromaire, M.C., de Gouvello, B., Saad, M., Chebbo, G., 2009. Annual Metallic Flows in Roof Runoff from Different Materials: Test-Bed Scale in Paris Conurbation. Environ. Sci. Technol. 43, 5612- 
5618. doi:10.1021/es9002108

Sage, J., Bonhomme, C., Al Ali, S., Gromaire, M.-C., 2015. Performance assessment of a commonly used "accumulation and wash-off" model from long-term continuous road runoff turbidity measurements. Water Res. 78, 47-59. doi:http://dx.doi.org/10.1016/j.watres.2015.03.030

Schoups, G., Vrugt, J.A., 2010. A formal likelihood function for parameter and predictive inference of hydrologic models with correlated, heteroscedastic, and non-Gaussian errors. Water Resour. Res. 46. doi:10.1029/2009WR008933

Schriewer, A., Horn, H., Helmreich, B., 2008. Time focused measurements of roof runoff quality. Corros. Sci. 50, 384-391. doi:10.1016/j.corsci.2007.08.011

Thyer, M., Renard, B., Kavetski, D., Kuczera, G., Franks, S.W., Srikanthan, S., 2009. Critical evaluation of parameter consistency and predictive uncertainty in hydrological modeling: A case study using Bayesian total error analysis. Water Resour. Res. 45. doi:10.1029/2008WR006825

Tsihrintzis, V.A., Hamid, R., 2001. Modeling and Management of Urban Stormwater Runoff Quality: A Review. Water 11, 137-164. doi:10.1023/A:1007903817943

Van de Voorde, A., 2012. Incidence des pratiques d'entretien des toitures sur la qualité des eaux de ruissellement $\square$ : cas des traitements par produits biocides [Effect of roof maintenance practices on runoff quality $\square$ : case of biocidal treatments] (Ph.D. Thesis). Université Paris-Est (France).

Vezzaro, L., Mikkelsen, P.S., 2012. Application of global sensitivity analysis and uncertainty quantification in dynamic modelling of micropollutants in stormwater runoff. Environ. Model. Softw. 27-28, 40-51. doi:http://dx.doi.org/10.1016/j.envsoft.2011.09.012

Vezzaro, L., Sharma, A.K., Ledin, A., Mikkelsen, P.S., 2015. Evaluation of stormwater micropollutant source control and end-of-pipe control strategies using an uncertainty-calibrated integrated dynamic simulation model. J. Environ. Manage. 151, 56-64. doi:http://dx.doi.org/10.1016/j.jenvman.2014.12.013

Wang, Q.J., Shrestha, D.L., Robertson, D.E., Pokhrel, P., 2012. A log-sinh transformation for data normalization and variance stabilization. Water Resour. Res. 48. doi:10.1029/2011WR010973

Wicke, D., 2014. Effect of age and rainfall pH on contaminant yields from metal roofs. Water Sci. Technol. 69, 2166-2173. doi:10.2166/wst.2014.124

Yang, J., Reichert, P., Abbaspour, K.C., 2007. Bayesian uncertainty analysis in distributed hydrologic modeling: A case study in the Thur River basin (Switzerland). Water Resour. Res. doi:10.1029/2006WR005497

Yaziz, M.I., Gunting, H., Sapari, N., Ghazali, A.W., 1989. Variations in rainwater quality from roof catchments. Water Res. doi:10.1016/0043-1354(89)90211-X

Zhang, X., He, W., Odnevall Wallinder, I., Pan, J., Leygraf, C., 2002. Determination of instantaneous corrosion rates and runoff rates of copper from naturally patinated copper during continuous rain events. Corros. Sci. 44, 2131-2151. doi:http://dx.doi.org/10.1016/S0010-938X(02)00015-X

Zobrist, J., Müller, S.R., Ammann, A., Bucheli, T.D., Mottier, V., Ochs, M., Schoenenberger, R., Eugster, J., Boller, M., 2000. Quality of roof runoff for groundwater infiltration. Water Res. 34, 1455-1462. 
doi:10.1016/S0043-1354(99)00290-0 